\title{
Hydrogen Enhances the Stability of Glutamic Acid In Hydrothermal Environments
}

\author{
Namhey Lee ${ }^{\mathrm{a}, \mathrm{b} *}$, Dionysis I. Foustoukos ${ }^{\mathrm{b}}$, Dimitri A. Sverjensky ${ }^{\mathrm{a}, \mathrm{b}}$, \\ Robert M. Hazen ${ }^{\mathrm{b}}$ and George D. Cody ${ }^{\mathrm{b}}$
}

${ }^{a}$ Dept. of Earth and Planetary Sciences, Johns Hopkins University, Baltimore, MD 21218, USA.

${ }^{\mathrm{b}}$ Geophysical Laboratory, Carnegie Institution of Washington, 5251 Broad Branch Road NW, 20015, USA.

*Correspondence to: namheyl@jhu.edu

The potential for chemical evolution of complex organic molecules such as peptides in hydrothermal environments requires the persistence of the component amino acids under such conditions. Here, we show experimentally that the redox state (activity of $\mathrm{H}_{2}$ ) of the aqueous fluids plays a key role in the stability of glutamic acid during hydrothermal processes. The results demonstrate that highly reducing redox conditions imposed by elevated concentrations of dissolved $\mathrm{H}_{2}$ suppress the oxidative decomposition of glutamic acid at elevated temperatures. Our experimental data support proposals that amino acids may persist, albeit metastably, under geochemically relevant hydrothermal conditions. The reduced nature of deep-sea vent fluids might have been a critical parameter in sustaining the needed ingredients for the origin of life on the early Earth, and may currently play a role in facilitating the persistence of biomolecules supporting heterotrophic microbial communities in modern near-seafloor hydrothermal environments.

Key words: Hydrogen, amino acids, hydrothermal conditions, origin of life

\section{Introduction}

Origin of life scenarios that focus on deep-sea hydrothermal vent environments highlight the exceptional physicochemical conditions where small organic molecules such as amino acids may form abiotically and condense into primitive macromolecules (Amend and Shock, 1998; Cody, 2004; Huber and Wächtershäuser, 1998; Milner-White and Russell, 2011; Russell et al., 2005; Shock, 1992; Shock and Canovas, 2010). Sub-seafloor hydrothermal circulation within the oceanic crust generally results in hydrothermal vent fluids characterized by elevated temperatures, a wide range of $\mathrm{pH}$, and highly reducing conditions indicated by the presence of dissolved $\mathrm{H}_{2}$. The stability of amino acids in these environments is essential if such simple molecules are to form peptides. Some studies have shown very promising routes to oligopeptide 
synthesis occurring at room temperature and under hydrothermal conditions (Huber et al., 2003; Leman et al., 2004). However, numerous experimental studies have reported that amino acids are intrinsically unstable under hydrothermal conditions (Andersson and Holm, 2000; Bada et al., 1995; Cox and Seward, 2007; Lemke, 2009; Miller and Bada, 1988). In contrast, theoretical calculations point to the possibility of metastable equilibria between amino acids and $\mathrm{CO}_{2}-\mathrm{NH}_{3}$ in $\mathrm{H}_{2}$-enriched hydrothermal vent fluids (Shock, 1990; Shock and Canovas, 2010). This possibility has been investigated experimentally by only one study (Andersson and Holm, 2000) where it was shown that the decomposition rates of amino acids at $200{ }^{\circ} \mathrm{C}$ were suppressed in the presence of mineral assemblages intended to buffer the $\mathrm{H}_{2}$ concentration in the fluids. However, kinetic barriers can prevent equilibrium with mineral buffer assemblages at $200{ }^{\circ} \mathrm{C}$; thus, the actual $\mathrm{H}_{2}$ content in the fluid, which was not measured, may have been well below the intended equilibrium values. No experimental hydrothermal study of amino acid stability has been reported in which a known $\mathrm{H}_{2}$ concentration was imposed at levels relevant to modern deep-sea hydrothermal vent systems.

Here we report experimental results that show the effect of $\mathrm{H}_{2 \text { (aq) }}$ on the hydrothermal stability of glutamic acid. Two sets of homogeneous experiments were conducted at $200{ }^{\circ} \mathrm{C}$ and $250{ }^{\circ} \mathrm{C}$ at 140 bars. First, we followed the decomposition of glutamate in water without added $\mathrm{H}_{2(\text { (aq) }}$ and initial $\mathrm{pH}_{25^{\circ} \mathrm{C}} \sim 10$. A second experiment was conducted involving aqueous solutions enriched with $13.1 \pm 1.8 \mathrm{mM}$ dissolved $\mathrm{H}_{2(\mathrm{aq})}$ at the same initial $\mathrm{pH}$. Measurements were made

on the decomposition products of glutamic acid. Overall, these conditions of $\mathrm{T}, \mathrm{P}, \mathrm{pH}$ or $\mathrm{H}_{2 \text { (aq) }}$ are similar to those in some natural ultramafic-hosted hydrothermal systems such as the Lost City hydrothermal vents at $30^{\circ} \mathrm{N}$ on the Mid-Atlantic Ridge (Foustoukos et al., 2008; Kelley et al., 2005; Seyfried et al., 2004).

\section{Materials and Methods}

\subsection{Materials}

All solutions were made from milli-Q water (Millipore resistance 17.9 Mega ohm). Lglutamic acid (Acros Organics, 99\%) and L-pyroglutamic acid (Aldrich, 99.0\%) were used without any further purification. The solutions were sonicated for more than 15 minutes and visually checked prior to the use to ensure complete dissolution. The $\mathrm{pH}$ was adjusted to alkaline values (i.e. 10) by adding precise volumes of standardized $\mathrm{NaOH}$. Measurement of $\mathrm{pH}$ was 
carried out using a combination electrode (Thermo-Electron, Orion 8103 BNUWP) that was previously calibrated with standardized $\mathrm{pH}$ buffers. Argon gas was constantly purged through the solution to avoid contamination by atmospheric $\mathrm{CO}_{2}$ prior to the experiments. The solution was kept under argon headspace.

The high initial $\mathrm{pH}$ of the glutamate solution was also chosen to provide minimal interaction with the $\mathrm{TiO}_{2}$ reactor surface layers (See below) (Maielle and Brill, 1998). It is known that $\mathrm{TiO}_{2}$ has a point of zero charge $\left(\mathrm{pH}_{\mathrm{pzc}}\right.$ ) near 5.4 at $25^{\circ} \mathrm{C}$ (Foustoukos et al., 2011; Jonsson et al., 2009) and that it decreases with increasing temperature (Machesky et al., 1998). The in-situ pHs were estimated using an aqueous speciation model (Shock and Helgeson, 1990; Shock et al., 1989; Wolery, 1992). The calculations show that at $250^{\circ} \mathrm{C}$, the $\mathrm{pH}$ range of the glutamate solution is around $7 \pm 0.5$ for all solutions (neutral $\mathrm{pH}$ at $250^{\circ} \mathrm{C}$ is 5.58 ). Additionally, $\mathrm{pHs}$ of the quenched fluid were measured to be around $\sim 9.7$. Preliminary calculations show that its quenched $\mathrm{pH}$ is consistent with the model high- temperature $\mathrm{pH}$. Consequently, we can expect that glutamate has negligible interactions with $\mathrm{TiO}_{2}$ at the $\mathrm{pH}$ values of our experiments due to electrostatic repulsion (Jonsson et al., 2009).

\subsection{Experimental setup}

The hydrothermal flow-through experiments were performed by using two titanium flowthrough cells configured in-series and by following procedures similar to those described in Foustoukos et al., (2011) and Lee et al., (2014) (Fig. 1). The titanium reactors/pressure tubing were combusted in air to generate inert $\mathrm{TiO}_{2}$ layers clearly evident by the blue color prior to the experiments. The initial L-glutamic acid solution $(9.6 \mathrm{mM}, \mathrm{pH}=10)$ was first introduced into a $50 \mathrm{ml}$ titanium pressure vessel (Reaction cell\#1) (Autoclave Engineers). Once headspace was created in the pressure vessel and highly pressurized $\mathrm{H}_{2(\mathrm{~g})}$ was introduced, it was allowed to dissolve at elevated concentrations by a magnetic agitator operating at high pressure at 600 revolutions/minute at room temperature. Time series sampling indicated that 36 bar of $\mathrm{H}_{2(\mathrm{~g})}$ at the headspace resulted in nearly $13 \mathrm{mM}$ of dissolved $\mathrm{H}_{2}$ within 30 minutes of agitation. It should be noted that due to the limited volume of reaction cell\#1, fluid was depleted and replenished separately for each flow rate. Consequently, the dissolved $\mathrm{H}_{2}$ concentrations may have differed slightly between flow rates, yielding an average of $13.1 \pm 1.8 \mathrm{mM}$ (Table 1,2). The $\mathrm{H}_{2}$-enriched solution was delivered to the reactor cell \#2 (fixed volume of $3.55 \mathrm{ml}$ ) located inside a gravity- 
convection Lindberg/Blue oven (with temperature uniformity of $4{ }^{\circ} \mathrm{C}$ at $200{ }^{\circ} \mathrm{C}$ ). Fluid delivery was facilitated by a high-precision dual-cylinder gas-tight titanium pump (Quizix SP5000) at constant flow rate of between 0.1 to $1.4 \mathrm{ml} / \mathrm{min}$, while maintaining constant pressure conditions (140 bar) by an inline titanium backpressure regulator (Coretest DBPR-5). Flow rates determined the residence time of the fluid in the high temperature Ti-reactor cell \#2. Accordingly, samples were taken at different reaction times with gas tight syringes.

Three different types of ionic chromatography (IC) were adopted for aqueous species analyses. For the detection and measurement of amino acids and other anionic organic molecules a Dionex ICS-5000 AAA-Direct IC was used. The chromatograph was equipped with a 2-250 AminoPac PA 10 analytical column and an integrated pulsed amperometry electrochemical detector (IPAD). Aliphatic decomposition products such as formate and pyroglutamate were analyzed with a Metrohm MIC-3 Advanced ionic chromatograph equipped with a Metrosep A sup 7-250 column and conductivity detector. Cationic decomposition products such as ammonium ion were monitored and analyzed with the Dionex ion chromatograph ICS-5000 using a 250 IonPac CS12A analytical column and conductivity detector. For ammonium analyses, the sample aliquots were acidified immediately upon the collection and kept in the refrigerator for later analyses. The eluent for cation IC was methanesulfonic acid with the $\mathrm{pH}$ of $\sim 1.5$ which allows us to measure ammonia species all in ammonium form consistently.

Dissolved gases were analyzed using Shimadzu gas chromatography equipped with thermal conductivity detector and a Carboxen-1010 Plot/Silica column. The fluid sample was collected in a pre-acidified syringe to ensure the complete conversion of dissolved carbonated species into $\mathrm{CO}_{2(\mathrm{~g})}$ followed by headspace extraction of the sample syringe with Ar gas.

Gas chromatography-mass spectroscopy (GC-MS) by Agilent-6890N was used on selected samples to detect trace amount of decomposition products. The sample aliquots were dried overnight at $60{ }^{\circ} \mathrm{C}$ on a hot plate to remove water. Then the hydroxyl groups were derivatized using $\mathrm{N}$-(tert-butyldimethylsilyl)-N-methyltrifluoroacetamide (MTBSTFA) and acetonitrile and consequently diluted with dichloromethane (DCM) and analyzed. With this method, we were able to identify succinate, glutaconate, and $\alpha$-hydroxyglutarate. Quantification of trace amount of these organic molecules is not trivial as it involves series of sample processing that may introduce uncertainities. For this reason, we chose two longest reaction time 
samples to quantify the succinic acid to illustrate the difference between with and without $\mathrm{H}_{2}$ present experimental conditions.

\section{Results and Discussion}

It is well known that glutamic acid solutions at high temperatures spontaneously undergo intramolecular cyclization via a dehydration reaction to form pyroglutamic acid. This is a redox neutral, reversible reaction (Povoledo and Vallentyne, 1964). For example, at $250{ }^{\circ} \mathrm{C}$, our experimental data indicate that within 5 minutes, the reaction reaches a steady state in which pyroglutamate predominates (Supplementary Materials Figure 1S).

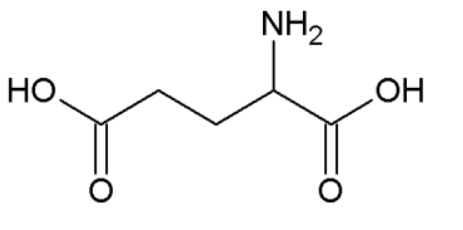

Glutamic acid

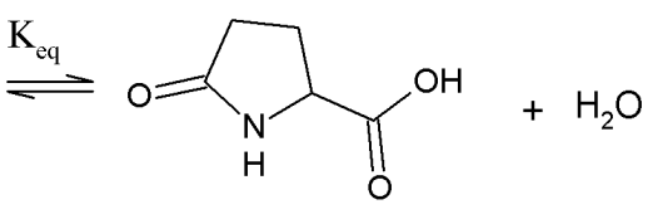

Pyroglutamic acid

Reaction (1)

However, in addition to reaction (1), hydrothermal decomposition of the glutamate and/or pyroglutamate is clearly evident in that we observe the formation of formate, ammonia, $\mathrm{CO}_{2(\mathrm{aq})}$ and $\mathrm{H}_{2(\mathrm{aq})}$. Additional decomposition products detected include glutaconic acid, $\alpha$ hydroxyglutaric acid and, interestingly, succinic acid. We searched for but did not detect $\gamma$ aminobutyric acid, acetate, or glutamylglutamate. In our control experiment where no $\mathrm{H}_{2(\mathrm{aq})}$ was added, the concentrations of the decomposition products increased progressively with reaction time and temperature (Figs. 2 and 3). These results are consistent with previous studies that demonstrate the instability of amino acids in hot water (Andersson and Holm, 2000; Cox and Seward, 2007; Lemke, 2009; Miller and Bada, 1988). However, in our $\mathrm{H}_{2}$-bearing experiments, the concentrations of decomposition products remained low and essentially constant with reaction time. Specifically, in Figs. $2 \mathrm{a}$ and b, it is shown that at $200{ }^{\circ} \mathrm{C}$, when no $\mathrm{H}_{2(\mathrm{aq})}$ was added, $\mathrm{CO}_{2(\mathrm{aq})}$ increased from $0.15 \pm 0.10$ to $0.45 \pm 0.22$ mmolal over the reaction time of 2.5 to 35.5 minutes, and formate also increased from $12 \pm 0.7$ to $17 \pm 0.1 \mu \mathrm{M}$. However, for the $\mathrm{H}_{2^{-}}$ enriched system, $\mathrm{CO}_{2(\mathrm{aq})}$ generation was suppressed to $0.15 \pm<0.02$ mmolal throughout the reaction time and formate was suppressed to $4.3 \pm 0.6$ to $14 \pm 0.7 \mu \mathrm{M}$. These trends are even more marked at $250{ }^{\circ} \mathrm{C}$. For example, it can be seen in Figs. $2 \mathrm{c}$ and $\mathrm{d}$ that without $\mathrm{H}_{2(\mathrm{aq})}$ added to the solution, $\mathrm{CO}_{2(\mathrm{aq})}$ increased from $0.18 \pm 0.07$ to $0.58 \pm 0.2$ mmolal and formate increased from $43 \pm 0.1$ to $64 \pm 6.4 \mu \mathrm{M}$. In contrast, in the presence of dissolved $\mathrm{H}_{2}$, the $\mathrm{CO}_{2(\mathrm{aq})}$ generation was 
suppressed to a constant value of about $0.19 \pm 0.03$ mmolal and the formate was limited to only about $18 \pm 0.8 \mu \mathrm{M}$.

The yield of ammonium ion also exhibited a dependence on redox state. It is shown in Fig. 3a that in the $\mathrm{H}_{2(\mathrm{aq})}$-free experiment, ammonium ion concentration increased progressively from $17.3 \pm 0.5$ to $92.4 \pm 1.5 \mu \mathrm{M}$. However, for the $\mathrm{H}_{2}$-bearing system, ammonium production was limited to $20 \sim 50 \mu \mathrm{M}$. The deamination reaction itself is a redox independent and reversible reaction as shown for very similar amino acid - aspartate (Bada and Miller, 1968), yet the yield of ammonium ion also exhibited a dependence on redox state. This is because for $\mathrm{H}_{2}$-bearing system, the accumulation of reaction products until $\alpha$-hydroxyglutaric acid leads to the overall shift of equilibrium towards the persistence of glutamate resulting in limited concentrations of ammonium production. We observed initial sharp increase in ammonium ion concentration for $\mathrm{H}_{2}$-bearing system, which is possibly related to the initial high availability of glutamate prior to the conversion to pyroglutamate (Fig. 3a).

Most importantly, the trace amounts of complex organic decomposition products provide a mechanistic explanation for the effect of $\mathrm{H}_{2(\mathrm{aq})}$ on the hydrothermal decomposition of glutamate. For example, we find that the concentrations of succinic acid are minimal under reducing conditions (Fig. 3b) often close to or below the detection limit. Hence, we report the succinate concentrations for the longest reaction time. In detail, without added $\mathrm{H}_{2}$, the amount of succinic acid produced was $1.8 \pm 0.1 \mu \mathrm{M}$ and $30 \pm 1.2 \mu \mathrm{M}$ at $200^{\circ} \mathrm{C}$ and $250^{\circ} \mathrm{C}$, respectively. However, in the presence of $\mathrm{H}_{2(\mathrm{aq})}$, succinic acid production was suppressed to $1.3 \pm 0.1 \mu \mathrm{M}$ at the longest reaction time for both temperatures. We address the significance of this below.

These experimental results reveal that the redox state imposed by dissolved hydrogen strongly influences the stability of glutamate. Based on the products detected, we propose the following reaction network for glutamic acid and its decomposition products under hydrothermal conditions (Fig. 4). Ignoring the equilibrium between glutamate and pyroglutamate (reaction (1)), glutamate undergoes rapid and reversible deamination to form cis- and trans-glutaconic acid. Subsequent hydration yields $\alpha$-hydroxyglutaric acid (both products were detected with GC-MS). The next step involves the dehydrogenation of $\alpha$-hydroxyglutaric acid to $\alpha$-ketoglutaric acid (Fig. 4). This is the key redox-sensitive reaction that is strongly influenced by the concentration of dissolved $\mathrm{H}_{2(\mathrm{aq})}$. The $\alpha$-ketoglutaric acid then undergoes irreversible oxidative decarboxylation to succinic and formic acids, a reaction typical of $\alpha$-keto acids under hydrothermal conditions 
(Siegel and Lanphear, 1979). We did not detect $\alpha$-ketoglutaric acid as the conversion to succinic acid is fast reaction, but its presence was inferred from the presence of succinic acid. The final step in the reaction network involves formic acid reacting to $\mathrm{CO}_{2}$ and $\mathrm{H}_{2}$.

This reaction sequence is important because in the absence of dissolved hydrogen, glutamate will be lost through the irreversible decarboxylation of $\alpha$-ketoglutaric acid. Indeed, we observe a continuous increase of the reaction products $\mathrm{CO}_{2}, \mathrm{H}_{2}$, and formic acid with reaction time and temperature. However, in $\mathrm{H}_{2}$-enriched aqueous solutions the dehydrogenation of $\alpha$ hydroxyglutaric acid to $\alpha$-ketoglutaric acid is inhibited, or more likely, any $\alpha$-ketoglutaric acid formed is promptly reduced back to the $\alpha$-hydroxyglutaric acid. This reduction suppresses the irreversible decomposition of $\alpha$-ketoglutaric acid to succinic and formic acids (Cody et al., 2004). Consequently, limited production of $\mathrm{CO}_{2}$, formic and succinic acids is observed. The simultaneous decrease of the ammonium ion production indicates that the amount of glutaconic acid remains essentially constant. In other words, for the reaction network linking glutamate and $\alpha$-ketoglutaric acid, the presence of $\mathrm{H}_{2}$ serves to shift the reactions towards favoring the persistence of glutamate. The same reaction mechanism was shown to be applicable to near neutral $\mathrm{pH}$ conditions, supporting this mechanism to be the dominant reaction occurring under hydrothermal conditions (Lee et al., 2014). Our results are consistent with hydrothermal experimental studies that explored the importance of redox control on the evolution of organic reactions not involving amino acids. Examples include $\mathrm{CO}_{2}$ reduction to $\mathrm{CO}$ and methanol using formic acid (Seewald et al., 2006) and the establishment of metastable equilibrium between ethylene and ethane using mineral buffers at 300-350 ${ }^{\circ} \mathrm{C}$ (Seewald, 1994, 2001).

\section{Concluding remarks}

In all scenarios postulated for the emergence of life (e.g. Russell et al., 2005), a stage is proposed wherein existing small organic molecules such as amino acids condense to form oligopeptides (Huber et al., 2003; Leman et al., 2004), ultimately enabling the emergence of catalytically active macromolecules. The present results show that high $\mathrm{H}_{2 \text { (aq) }}$ enhances the stability of amino acids, which should favor further reactions leading to greater chemical complexity, presumably a necessary requirement for the emergence of life early in Earth history.

These findings also have implications for life on the present day Earth. Modern deep sea hydrothermal vent fluids have 7 to 9 orders of magnitude higher $\mathrm{H}_{2 \text { (aq) }}$ than present-day ambient 
sea water (refer the reference in Shock and Canovas, 2010). The mixing between hydrothermal fluids and cold oxygenated seawater in near-seafloor environments induces redox gradients supporting chemolithoautotrophic metabolic processes in unique ecosystems of deep-sea microbial communities (Edwards et al., 2005). The persistence of these gradients is aided by the sluggish kinetics of abiotic hydrogen oxidation at temperatures lower than $250{ }^{\circ} \mathrm{C}$ (Foustoukos et al., 2011). If biomolecules such as amino acids persist in these environments, however, they could play a key role in the establishment of heterotrophic microbial communities in nonsedimented sites along the global ridge crests (Reysenbach et al., 2000; Summit and Baross, 2001; Ver Eecke et al., 2009). At high temperatures, these communities are mainly colonized by anaerobic thermophilic and hyperthermophilic Bacteria (Aquificales, Epsilonproteobacteria) and Archaea (Thermococcales) known to have versatile metabolisms, including heterotrophic respiration of peptides and amino acids (Holden et al., 2001; Huber et al., 2006). Such species have been proposed to populate the ultramafic-hosted biosphere at the Lost City vent site (Brazelton et al., 2006) in an ecosystem composed of both autotrophic and heteotrophic microorganisms. Thus, thermophilic ecological niches in hydrothermal vent fluids rich in dissolved $\mathrm{H}_{2 \text { (aq) }}$ and other reducing species could provide microbial communities with different

pathways for carbon incorporation. Within such dynamic, self-sustained ecosystems, the evolution of early stages of life on Earth might have thrived.

\section{Acknowledgements}

The authors greatly appreciate discussions with and assistance in the laboratory from $\mathrm{M}$. L. Fogel, I. Pérez-Rodríguez, H. J. Cleaves, K. Klochko, C. F. Estrada, and S. Ohara. In addition, N. Lee acknowledges inspirational advice from Bjørn Mysen in initiating this study. N. Lee and D. A. Sverjensky greatly appreciate the support of R. J. Hemley during their stay as visiting researchers at the Geophysical Laboratory. This research was conducted with support from the NSF OCE-0928443 (DF), NSF OCE-1038114 (DF), NSF EAR-1023865 (DAS), DOE DEFG02-96ER-14616 (DAS), NSF EAR-1023889 (RMH), NASA Astrobiology Institute, and the Carnegie Institution of Washington. 


\section{References:}

Amend, J.P., Shock, E.L., 1998. Energetics of Amino Acid Synthesis in Hydrothermal Ecosystems. Science 281, 1659-1662.

Andersson, E., Holm, N.G., 2000. The Stability of Some Selected Amino Acids Under Attempted Redox Constrained Hydrothermal Conditions Origins Life Evol. Biosphere 30, 9-23.

Bada, J.L., Miller, S.L., Zhao, M.X., 1995. The stability of amoni-acids at submarine hydrothermal vent temperatures. Origins Life Evol. Biosphere 25, 111-118.

Brazelton, W.J., Schrenk, M.O., Kelley, D.S., Baross, J.A., 2006. Methane- and sulfurmetabolizing microbial communities dominate the Lost City hydrothermal field ecosystem. Appl. Eviron. Microbiol. 72, 6257-6270.

Cody, G., 2004. Transition metal sulfides and the origins of metabolism. Annu. Rev. Earth. Pl. Sc. 32, 569-599.

Cox, J.S., Seward, T.M., 2007. The hydrothermal reaction kinetics of aspartic acid. Geochim. Cosmochim. Acta 71, 797-820.

Edwards, K.J., Bach, W., McCollom, T.M., 2005. Geomicrobiology in oceanography: microbemineral interactions at and below the seafloor. Trends. Micrbiol. 13, 449-456.

Foustoukos, D.I., Houghton, J.L., Seyfried, W.E., Sievert, S.M., Cody, G.D., 2011. Kinetics of $\mathrm{H} 2-\mathrm{O} 2-\mathrm{H} 2 \mathrm{O}$ redox equilibria and formation of metastable $\mathrm{H} 2 \mathrm{O} 2$ under low temperature hydrothermal conditions. Geochim. Cosmochim. Acta 75, 1594-1607.

Foustoukos, D.I., Savov, I.P., Janecky, D.R., 2008. Chemical and isotopic constraints on water/rock interactions at the Lost City hydrothermal field, $30^{\circ} \mathrm{N}$ Mid-Atlantic Ridge. Geochim. Cosmochim. Acta 72, 5457-5474.

Holden, J.F., Takai, K., Summit, M., Bolton, S., Zyskowski, J., Baross, J.A., 2001. Diversity among three novel groups of hyperthermophilic deep-sea Thermococcus species from three sites in the northeastern Pacific Ocean. FEMS. Microbiol. Ecol. 36, 51-60.

Huber, C., Eisenreich, W., Hecht, S., Wächtershäusher, G., 2003. A possible primordial peptide cycle. Science 301, 938-940.

Huber, C., Wächtershäuser, G., 1998. Peptides by activation of amino acids with $\mathrm{CO}$ on $(\mathrm{Ni}, \mathrm{Fe}) \mathrm{S}$ surfaces: Implications for the origin of life. Science 281, 670-672.

Huber, J.A., Butterfield, D.A., Baross, J.A., 2006. Diversity and distribution of subseafloor Thermococcales populations in diffuse hydrothermal vents at an active deep-sea volcano in the northeast Pacific Ocean. J. Geophys. Res.-Biogeo. 111.

Jonsson, C.M., Jonsson, C.L., Sverjensky, D.A., Cleaves II, H.J., Hazen, R.M., 2009. Attachment of 1-Glutamate to Rutile $(\alpha-\mathrm{TiO} 2)$ : A Potentiometric, Adsorption, and Surface Complexation Study. Langmuir 25, 12127-12135.

Kelley, D.S., Karson, J.A., Fruh-Green, G.L., Yoerger, D.R., Shank, T.M., Butterfield, D.A., Hayes, J.M., Schrenk, M.O., Olson, E.J., Proskurowski, G., Jakuba, M., Bradley, A., Larson, B., Ludwig, K., Glickson, D., Buckman, K., Bradley, A.S., Brazelton, W.J., Roe, K., Elend, M.J., Delacour, A., Bernasconi, S.M., Lilley, M.D., Baross, J.A., Summons, R.T., Sylva, S.P., 2005. A serpentinite-hosted ecosystem: The lost city hydrothermal field. Science 307, 1428-1434.

Lee, N., Foustoukos, D.I., Sverjensky, D.A., Cody, G.D., Hazen, R.M., 2014. The effect of temperature, $\mathrm{pH}$ amd redox state on the stability of glutamic acid in hydrothermal fluids. Geochim. Cosmochim. Acta 135, 66-86. 
Leman, L., Orgel, L., Ghadiri, M.R., 2004. Carbonyl sulfide-mediated prebiotic formation of peptides. Science 306, 283-286.

Lemke, K.H., Rosenbauer, R. J., Bird, D. K., 2009. Peptide synthesis in early earth hydrothermal systmes. Astrobiology 9, 141-146.

Machesky, M.L., Wesolowski, D.J., Palmer, D.A., Ichiro-Hayashi, K., 1998. Potentiometric titrations of rutile suspensions to 250 degrees C. J. Colloid Interface Sci. 200, 298-309.

Maielle, P.G., Brill, T.B., 1998. Spectroscopy of Hydrothermal Reactions. 10. Evidence of Wall Effects in Decarboxylation Kinetics of $1.00 \mathrm{~m} \mathrm{HCO} 2 \mathrm{X}(\mathrm{X}=\mathrm{H}, \mathrm{Na})$ at $280-330^{\circ} \mathrm{C}$ and 275 bar. J. Phys. Chem 102, 5886-5891.

Miller, S.L., Bada, J.L., 1988. Submarine hot springs and the origin of life. Nature 334, 609-611. Miler-White, E.J., Russell, M.J., 2011. Functional capabilities of the earliest peptides and the emergence of life. Genes 2, 671-688.

Milner-White, E.J., Russell, M.J., 2011. Functional capabilities of the earliest peptides and the emergence of life. Genes 2, 671-688.

Povoledo, D., Vallentyne, J.R., 1964. Thermal reaction kinetics of the glutamic acidpyroglutamic acid system in water. Geochim. Cosmochim. Acta 28, 731-734.

Reysenbach, A.L., Longnecker, K., Kirshtein, J., 2000. Novel bacterial and archaeal lineages from an in situ growth chamber deployed at a Mid-Atlantic Ridge hydrothermal vent. Appl. Eviron. Microbiol. 66, 3798-3806.

Russell, M.J., Hall, A.J., Boyce, A.J., Fallick, A.E., 2005. 100th anniversary special paper: On hydrothermal convection systems and the emergence of life. Econ. Geol. 100, 419-438.

Seewald, J.S., 1994. Evidence for metastable equilibrium between hydrocarbons under hydrothermal conditions. Nature 370, 285-287.

Seewald, J.S., 2001. Aqueous geochemistry of low molecular weight hydrocarbons at elevated temperatures and pressures: Constraints from mineral buffered laboratory experiments. Geochim. Cosmochim. Acta 65, 1641-1664.

Seewald, J.S., Zolotov, M.Y., McCollom, T., 2006. Experimental investigation of single carbon compounds under hydrothermal conditions. Geochim. Cosmochim. Acta 70, 446-460.

Seyfried, W.E., Foustoukos, D.I., Allen, D.E., 2004. Ultramafic-hosted hydrothermal systems at mid-ocean ridges: Chemical and physical controls on $\mathrm{pH}$, redox, and carbon reduction reactions, in mid-ocean ridges: Hydrothermal Interactions between the lithosphere and oceans. Geophys. Monogr. Ser. 148, 267-284.

Shock, E.L., 1990. Geochemical constraints on the origin of organic compounds in hydrothermal systems. Origins Life Evol. Biosphere 20, 331-367.

Shock, E.L., 1992. Stability of peptides in high-temperature aqueous solutions. Geochim. Cosmochim. Acta 56, 3481-3491.

Shock, E.L., Canovas, P., 2010. The potential for abiotic organic synthesis and biosynthesis at seafloor hydrothermal systems Geofluids 10, 161-192.

Shock, E.L., Helgeson, H.C., 1990. Calculation of the thermodynamic and transport-properties of aqueous species at high-pressures and temperatures - Standard partial molal properties of organic-species. Geochim. Cosmochim. Acta 54, 915-945.

Shock, E.L., Helgeson, H.C., Sverjensky, D.A., 1989. Calculation of the thermodynamic and transport-properties of aqueous species at high-pressures and temperatures - Standard partial molal properties of inorganic neutral species. Geochim. Cosmochim. Acta 53, 2157-2183. 
Siegel B., Lanphear J., 1979. Iron-catalyzed oxidative decarboxyltion of benzoylformic acid. J. Am. Chem. Society. 101, 2221-2222.

Summit, M., Baross, J.A., 2001. A novel microbial habitat in the mid-ocean ridge subseafloor. P. Natl. Acad. Sci. USA 98, 2158-2163.

Ver Eecke, H.C., Kelley, D.S., Holden, J.F., 2009. Abundances of Hyperthermophilic Autotrophic Fe(III) Oxide Reducers and Heterotrophs in Hydrothermal Sulfide Chimneys of the Northeastern Pacific Ocean. Appl. Eviron. Microbiol. 75, 242-245.

Wolery, T.J., 1992. EQ3NR, A Computer Program for Geochemical Aqueous SpeciationSolubility Calculations: Theoretical Manual, User's Guide, and Related Documentation (Version 7.0). Lawrence Livermore National Laboratory. 
Table 1. Concentrations of dissolved species attained in the experiments conducted at 200 $250{ }^{\circ} \mathrm{C}, 140 \mathrm{bar}$, and in absence of added $\mathrm{H} 2$. The symbol "-" indicates concentrations that were below the detection limits.

\begin{tabular}{|c|c|c|c|c|c|c|c|}
\hline & $T(\min )$ & Glutamate $(\mathrm{mM})$ & Pyroglutamate (mM) & Formate $(\mu \mathrm{M})$ & $\mathrm{CO}_{2 \max }(\mathrm{mM})$ & $\mathrm{H}_{2(x \mathbf{x})}(\mu \mathrm{M})$ & $\mathrm{NH}_{4}^{+}(\mu \mathrm{M})$ \\
\hline \multicolumn{8}{|l|}{ No $\mathrm{H}_{2}$ added } \\
\hline \multirow[t]{18}{*}{$T=200^{\circ} \mathrm{C}$} & 2.54 & 8.20 & & - & 0.08 & - & - \\
\hline & 2.54 & 8.48 & 2.16 & - & 0.12 & - & - \\
\hline & 2.54 & 8.52 & 2.25 & - & 0.23 & - & - \\
\hline & 3.55 & 6.85 & & - & 0.12 & - & - \\
\hline & 3.55 & 6.82 & 3.64 & - & 0.26 & - & - \\
\hline & 3.55 & 6.85 & 3.74 & - & & - & - \\
\hline & 4.44 & 5.44 & & - & 0.10 & - & - \\
\hline & 4.44 & 5.23 & 6.59 & - & 0.20 & - & - \\
\hline & 4.44 & 5.32 & 6.80 & - & 0.23 & - & - \\
\hline & 7.10 & 1.45 & & 12.1 & 0.12 & 1.7 & - \\
\hline & 7.10 & 1.00 & 8.30 & 12.2 & 0.14 & 1.4 & - \\
\hline & 7.10 & 1.27 & 8.26 & 13.3 & 0.16 & 0.6 & - \\
\hline & 11.83 & 0.57 & 8.35 & 16.9 & 0.31 & 1.5 & - \\
\hline & 11.83 & 0.38 & 8.70 & 16.6 & 0.21 & 1.1 & - \\
\hline & 11.83 & 0.59 & 8.91 & & 0.27 & 0.0 & - \\
\hline & 35.5 & 0.29 & 9.07 & 14.1 & 0.71 & 1.6 & - \\
\hline & 35.5 & 0.10 & & 15.8 & 0.34 & 2.5 & - \\
\hline & 35.5 & 0.28 & & 16.4 & 0.30 & 2.2 & - \\
\hline \multicolumn{8}{|l|}{$T=250^{\circ} \mathrm{C}$} \\
\hline & 2.54 & 4.75 & 5.10 & 35.0 & 0.14 & - & - \\
\hline & 2.54 & & 5.16 & & 0.14 & - & - \\
\hline & 2.54 & & 5.19 & & 0.25 & - & - \\
\hline & 3.55 & 1.31 & 8.10 & & 0.12 & - & - \\
\hline & 3.55 & & 8.09 & 41.5 & 0.29 & - & - \\
\hline & 3.55 & & 7.90 & 42.7 & 0.17 & - & - \\
\hline & 7.10 & 0.79 & 8.88 & 51.3 & 0.16 & 0.6 & 16.9 \\
\hline & 7.10 & & 9.00 & 50.2 & 0.26 & 0.7 & 17.6 \\
\hline & 7.10 & & 8.96 & 45.5 & 0.15 & - & 15.0 \\
\hline & 11.83 & 0.73 & 8.98 & 64.3 & 0.18 & 1.6 & \\
\hline & 11.83 & & 8.93 & & 0.25 & 1.3 & 28.5 \\
\hline & 11.83 & & 9.06 & 59.0 & 0.38 & 1.1 & 28.8 \\
\hline & 35.50 & 0.48 & 8.85 & 66.7 & 0.31 & 5.3 & 90.8 \\
\hline & 35.50 & & 8.78 & 68.0 & 0.78 & 4.1 & 93.7 \\
\hline & 35.50 & & 8.68 & 58.0 & 0.39 & 4.7 & 92.5 \\
\hline
\end{tabular}


Table 2. Concentrations of dissolved species meansured in the H2-enriched experiments conducted at 200-250, 140 bar. The symbols "." and "n.d." indicate concentrations that were below detection limits and "not determined", repsctively.

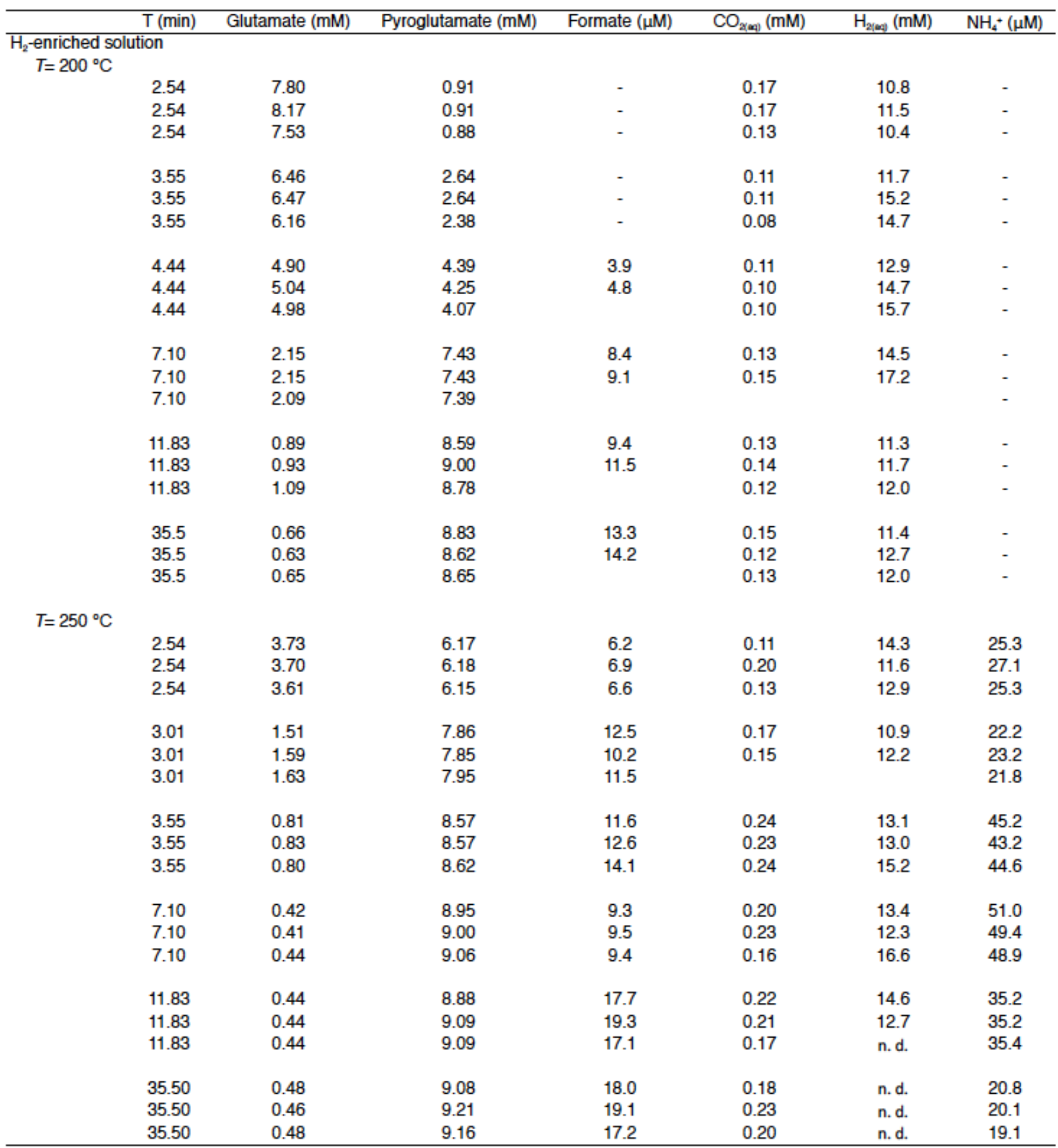


Figure 1.

Materials, experimental setup and methods

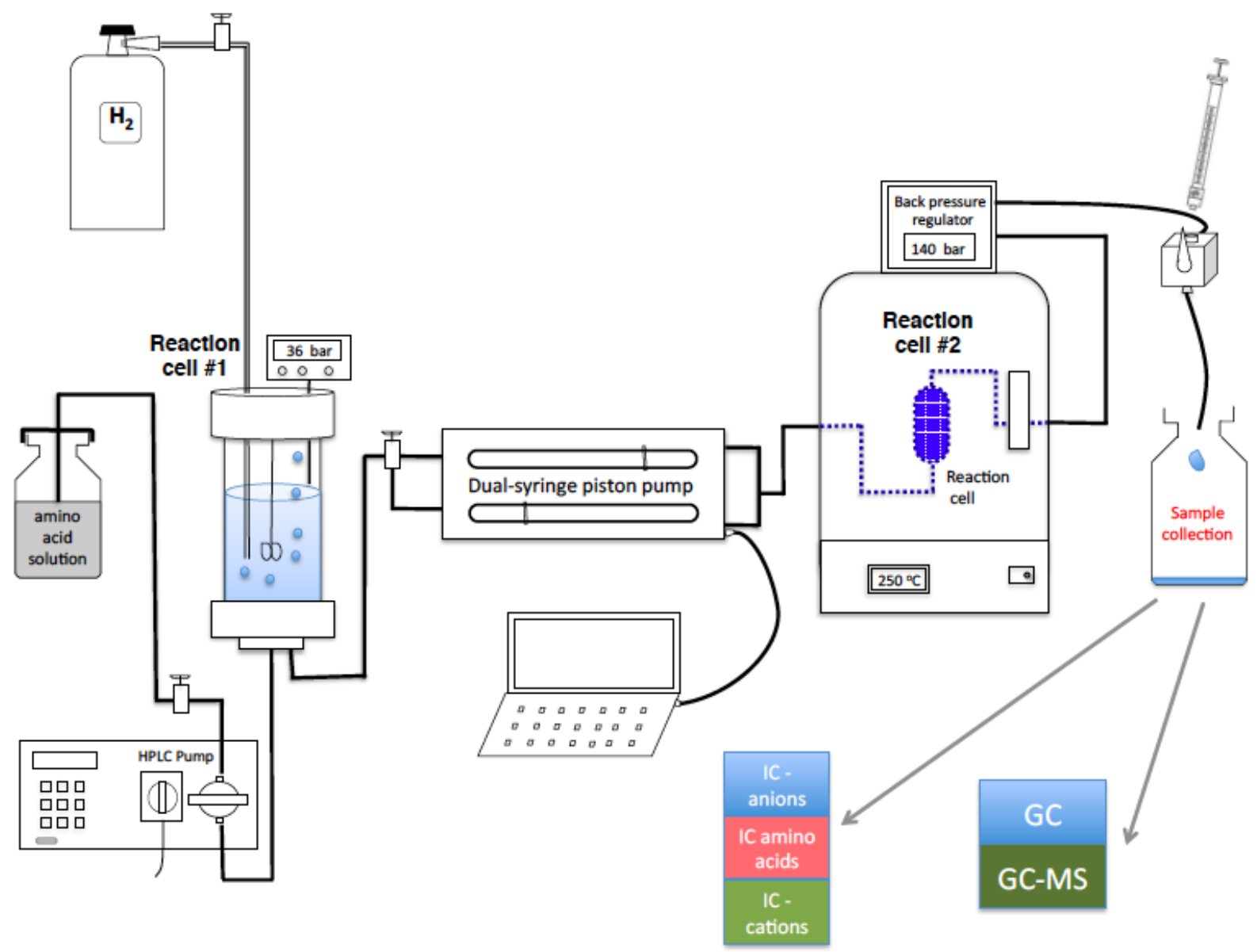


Figure 2. Dissolved $\mathrm{CO}_{2}$ and formate producted from the decomposition of glutamate/pyroglutamate at $200^{\circ} \mathrm{C}$ and $250^{\circ} \mathrm{C}$ with and without the presence of dissolved $\mathrm{H}_{2}$.

(a)

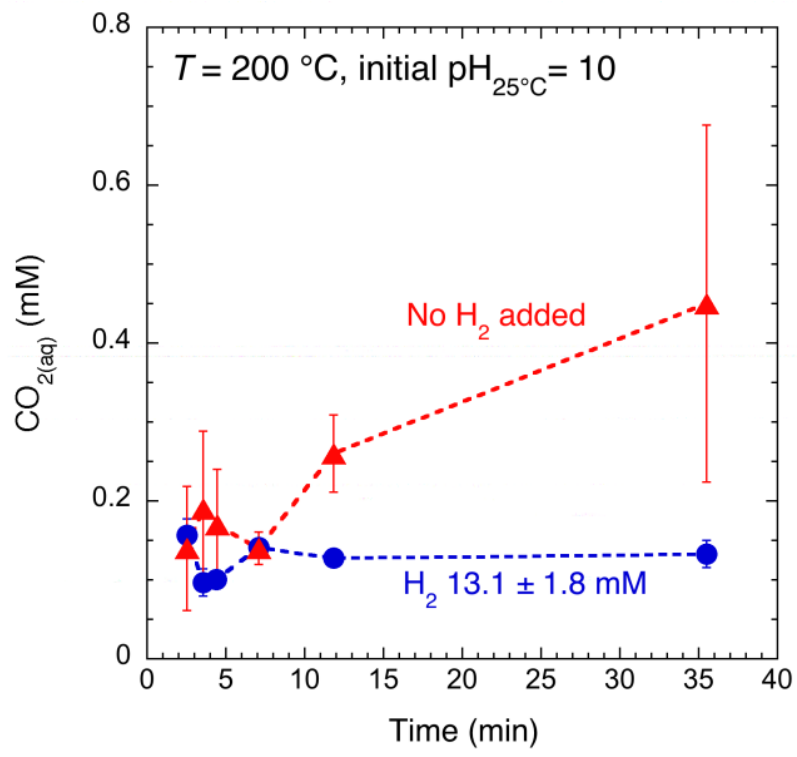

(c)

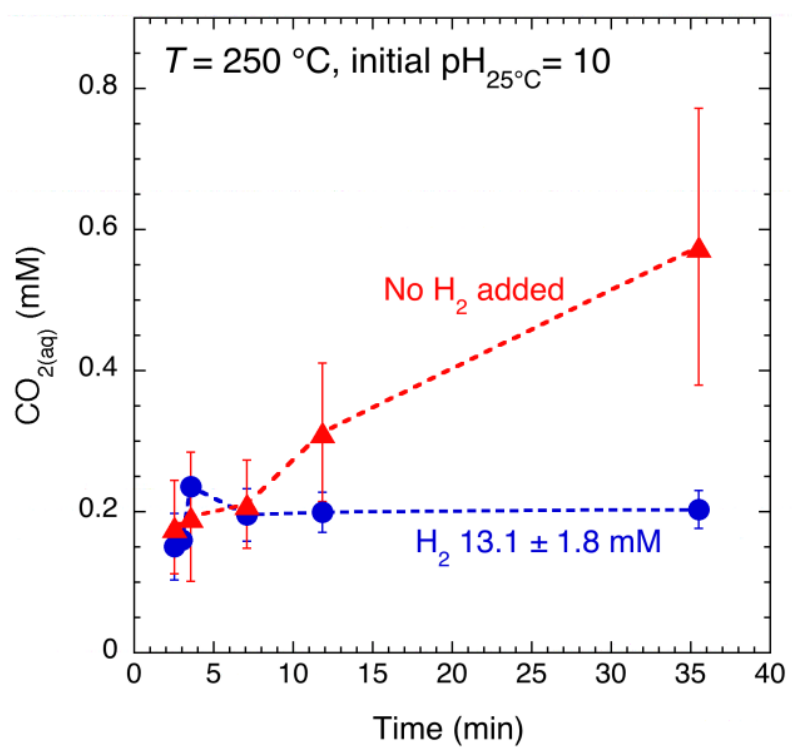

(b)

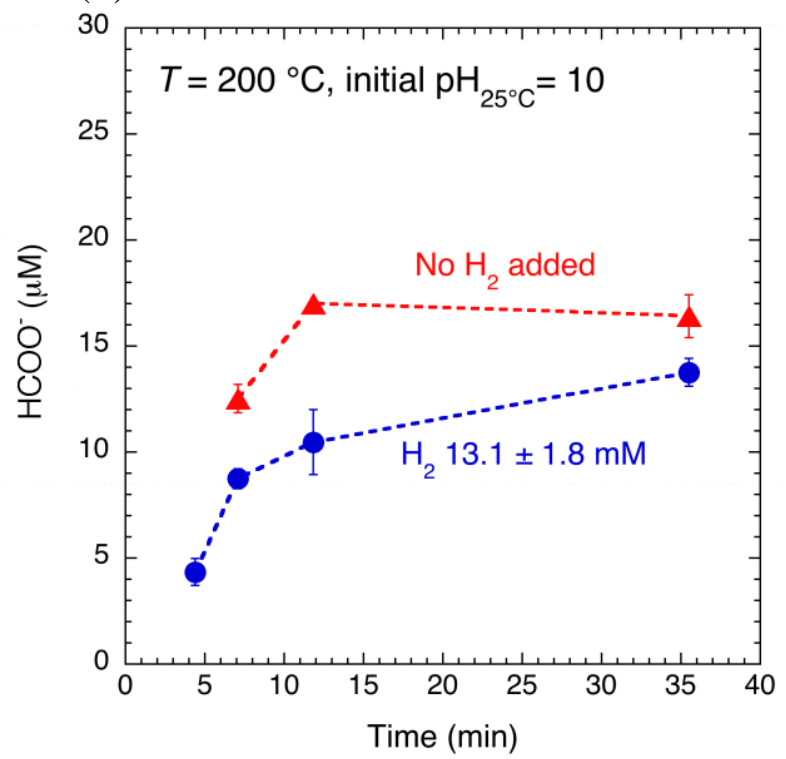

(d)

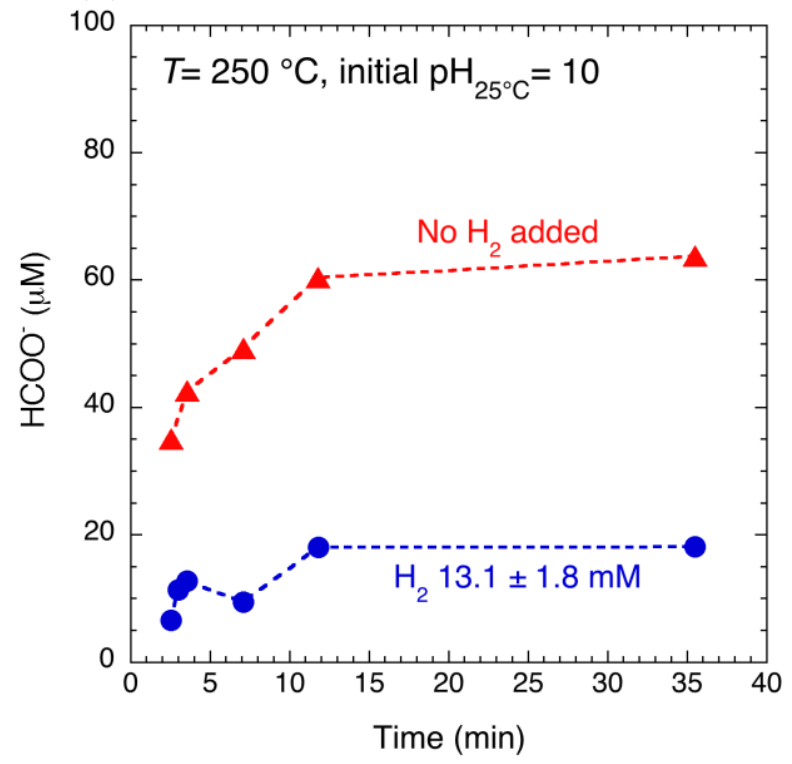


Figure 3. Concentrations of (a) ammonium ion (errors bars are within the symbols) and (b) succinic acid produced during hydrothermal decomposition of glutamate/pyroglutamate under controlled redox conditions. Succinic acid concentrations correspond to samples with the longest reaction time.

(a)

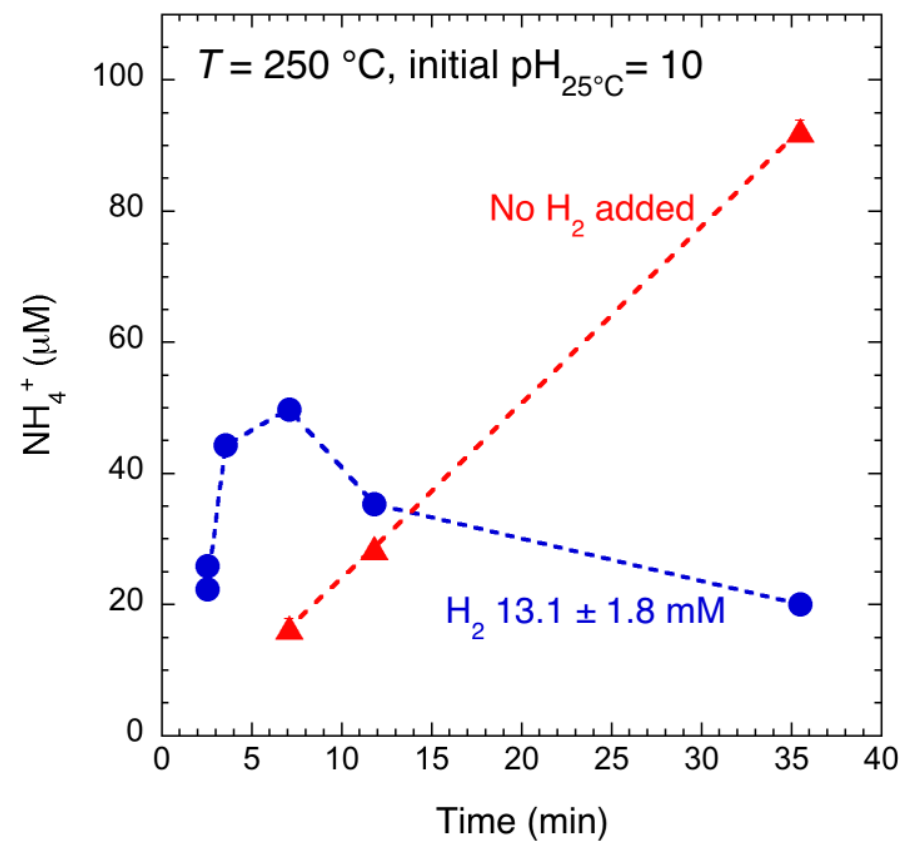

(b)

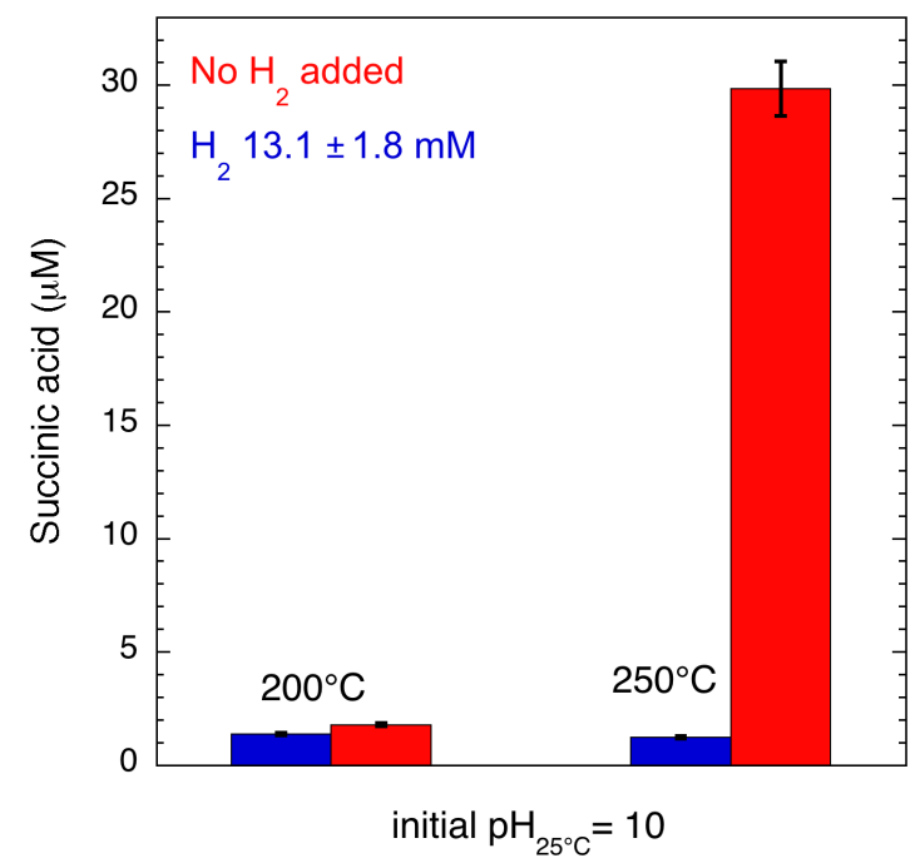


Figure 4. Reaction network for glutamic acid decomposition under hydrothermal conditions. Glutamic acid, pyroglutamic acid, formic acid, succinic acid, $\mathrm{CO}_{2(\mathrm{aq})}$ and $\mathrm{H}_{2(\mathrm{aq})}$ were quantitatively analyzed. Glutaconic and $\alpha$-Hydroxyglutaric acids were detected qualitatively using GC-MS.<smiles>[Y][C@H]1C=C[C@@H](C(=O)O)CC1</smiles>

Glutamic acid

Pyroglutamic acid<smiles>C=CC(N)=CC=CC(=O)O</smiles><smiles>C=CCC(=O)O</smiles>

Glutaconic acid $\alpha-$ Hydroxylglutaric acid $\alpha$-Ketoglutaric acid<smiles></smiles><smiles>O=CO</smiles><smiles>O=C(O)CCC(=O)O</smiles>

Formic acid Succinic acid 